\title{
Attitudes Towards Professional Psychological Help Seeking Among Young Adults in Kenya: Case Study of Public Teacher Training Colleges
}

\author{
Eunice Jemalel Nyavanga ${ }^{1,2, *}$, Mourice Barasa ${ }^{3}$ \\ ${ }^{1}$ The Technical University of Kenya, Faculty of Social Sciences and Technology, Department of Social and Human Development, Nairobi, \\ Kenya \\ ${ }^{2}$ Malel Bibwob Clinical Psychologists Consultancy (MICAP), Nairobi, Kenya \\ ${ }^{3}$ International Planned Parenthood Federation - Africa Region, Nairobi, Kenya
}

Email address:

enyavanga@yahoo.com (E. J. Nyavanga),barazam@gmail.com (M. Barasa)

${ }^{*}$ Corresponding author

\section{To cite this article:}

Eunice Jemalel Nyavanga, Mourice Barasa. Attitudes Towards Professional Psychological Help Seeking Among Young Adults in Kenya: Case Study of Public Teacher Training Colleges. Psychology and Behavioral Sciences. Vol. 5, No. 3, 2016, pp. 69-76.

doi: $10.11648 /$ j.pbs.20160503.12

Received: May 31, 2016; Accepted: June 7, 2016; Published: June 18, 2016

\begin{abstract}
The objective of this study was to determine the attitudes towards professional psychological help seeking among young adults in Kenya. A self completed questionnaire made up of demographic characteristics and Attitudes towards Professional Psychological Help Seeking scale (ATPPHS) was used to collect data from 2777 young adults training in four selected public teacher training colleges. Unfavorable attitudes towards professional psychological help seeking were identified among these participants. Significant variations were indicated in year of study, gender, marital status and whether they ever taught before coming to college in both summative and factor scores of ATPPHS. Young adults students hold more negative attitudes towards psychological professional help seeking for a mental illness in Kenya. The Study recommended on psychoeducation on both mental illness and expectations about counseling to improve help seeking behaviour.
\end{abstract}

Keywords: Attitudes, Professional Psychological Help Seeking, Teacher Trainees, Young Adults

\section{Introduction}

Mental illness is a leading cause of disability (45\%) among young adults, [1] yet nearly two-thirds of individuals with a diagnosable mental illness do not seek help, [2]. Individuals with mental illness experience significant disabilities including limitation of functioning at the personal, physical and society levels, [3] poor quality of life and impaired social functioning as their families and the communities are affected badly, [4]. Attitudes for professional help seeking have been identified as one major reason for not seeking help, [5].

Some studies in Psychiatric Morbidity among teachers have indicated higher levels compared to the general population. A study in the Kingdom of Saudi Arabia among secondary school female teachers indicated a high prevalence of psychiatric morbidity at 59.4\%, [6].

A study by the author Nyavanga et al (unpublished work) [7] indicated a prevalence of psychiatric morbidity of $41.3 \%$ among public primary school teachers in a rural District in Kenya. Similarly, Ani et al, [8] in a study among teacher trainees in Nigeria found out that this population experienced a lot of distress that led them to adopt religious practices to be able to cope at the highest year level of study. Other studies on teachers have also indicated a higher psychiatric morbidity, [9].

The World Health Organization (WHO) [10] has documented that mental health among young adults was a predictor of physical health. Young adults are still in their formative years and are open to addressing mental health issues, [11]. Similarly, globally college students have been found to be reluctant in seeking psychological help form professionals for mental health related issues, [12, 13, 14]. 
Attitudes towards professional psychological help-seeking are crucial in planning of both psychiatric and psychological services and in development and implementation of policy regarding the mentally ill, [15]. Previous studies have indicated that cultural and traditional beliefs, age, year of study, and lack of services influences help seeking behavior among college students, $[16,17]$.

There has not been much research done in this area in Africa, and this study will be able to document attitudes of professional psychological help seeking among the young adults and college students in Kenya.

Hypothesis

$\mathrm{H}_{\mathrm{O}}$ : Young adults in Kenya, have more unfavaourable / negative attitudes towards professional psychological help seeking for a mental illness.

$\mathrm{H}_{\mathrm{A}}$ : Young adults in Kenya have more favourable / positive attitudes towards professional psychological help seeking for a mental illness.

\section{Methodology and Study Design}

\subsection{Overall Objectives}

The study aimed at determining the attitudes towards professional psychological help seeking for a mental illness among young adults in Kenya- a case study of primary school teacher trainees.

\subsection{Measures}

\subsubsection{Demographics}

Participants were asked to indicate their gender, age, year of study, religion, marital status, whether they grew up in a rural or urban setting and whether they had ever taught before coming to college.

\subsubsection{Attitudes Towards Professional Psychological Help Seeking}

Attitudes Towards Seeking Professional Psychological Help (ATPPHS) Scale developed by Fischer and Turner, 1970 was used to measure this variable. This Scale is made up of 29 Likert scale items, with 11 items positively stated and 18 items $(1,3,4$, $6,8,9,10,13,14,15,17,19,20,21,22,24,26 \& 29)$ negatively stated. The Likert scale utilizes a 4-Point scale (1=disagree, $2=$ probably disagree, $3=$ probably agree and $4=$ agree) designed to assess general attitudes toward seeking professional help for a psychological and mental health problems.

A high total score, after reverse scoring the negative items, represents a positive/ more favourable attitudes towards professional psychological help seeking and these scores may range between 29 to 116 . To ease scoring, Fisher and Turner [17] classified scores into three categories based on the total scores obtained. Low Scorers (29-49), express negative attitudes towards seeking help for themselves or significant others, medium scorers (50-63), acknowledge that professional help can be useful but are unsure about their willingness to use it and high scorers (64-87) express positive attitudes towards seeking and using professional help, [17].
This scale has been subdivided into four main factors of Tolerance of the Stigma Associated with Psychological Help (STIGMA), Recognition of Personal Need for Professional Help (RECOG), Interpersonal Openness Regarding Ones Problems (OPEN) and Confidence in the Mental Health Professional (CONFID).

In this study, Salim's [17] adaptation of minor changes on Fishers original scale were made in the original scale by substituting the terms psychiatrists and psychiatric with counselors and psychologists respectively because of the fact that this study focus on psychological help, not psychiatric help. The scale items load on the different factors (subscales) as follows:

(1) Factor One - Tolerance of the Stigma Associated with Psychiatric Help (STIGMA)

This is a five (5) item factor $(3,14,20,27 \& 28)$ that estimates ones forbearance of the shame attached to psychological help seeking. This factor assesses participants' ability to forebear the stigma associated with psychotherapy. The highest possible score is 25 while the lowest score possible is 5 . Low scorers are less able to forebear such stigma. High scorers are more indifferent to such stigma, indicating a stronger tendency to seek professional help. Low scores indicate sensitivity to others' opinions regarding the need to visit a health professional. High scores express concern for freedom.

(2) Factor Two - Recognition of Personal Need for Professional Help (RECOG):

This is an eight (8) item factor $(4,5,6,9,18,24,25 \& 26)$, which taps the participants' awareness of need for professional psychological help. The highest possible score is 32 and the lowest possible score is 8 . Low scorers do not see the necessity to seek psychotherapeutic help for emotional problems, expecting psychological problems to resolve themselves. High scorers believe that emotional stress and troubles should be resolved with psychotherapeutic help. Scoring low (negative) on this factor means seeing little necessity for professional help for emotional problems, believing that psychological conflicts resolve themselves. In contrast, high scores (positive) on the scale indicate the individual does not see the value in suffering alone through a period of emotional stress, and is acknowledging the possibility of seeking professional help in the future.

(3) Factor Three - Interpersonal Openness Regarding Ones Problems (OPEN)

This is a seven (7) item factor $(7,10,13,17,21,22 \& 29)$ which describes ones willingness (interpersonal openness), to reveal ones personal problems to others. Participants are expected to rate their willingness to reveal problems to others including a mental health practitioner. The highest possible score is 28 while the lowest score possible is 7 . High scorers on this factor reveal to others personal problems more readily than low scorers, indicating their belief that one should speak to others about personal problems.

(4) Factor Four - Confidence in the Mental Health Profession (CONFID).

This is a nine (9) item factor $(1,2,8,11,12,15,16,19$ \& 23) that assesses participants trust in the mental health 
professional. Higher scores indicate positive attitudes. The highest possible score is 36 while the lowest score possible is 9. High scores indicate a more favourable attitude towards seeking help.

The instructions to participate for ATSPPHS Scale asked the respondents to share their honest opinions regarding agreement and disagreement with several statements pertaining to mental health issues. For this study, the phrase-counseling centre" was used in place of mental hospital, "counseling " was used in place of psychotherapy and the phrase "college counselor" replaced psychiatrist and psychologist.

These researchers chose ATPPHS for this study because of (1) its reliability and validity, which has reported internal reliability coefficients of 0.86 and 0.83 as well as a test retest reliabilities ranging from 0.89 ( 5 days) to 0.73 ( 2 months) [18], (2) its frequent use as a research tool to measure helpseeking attitudes and (3) comparisons of versions of scale with similar variations in language have yielded analogous psychometric properties as the original scale [19]. The ATPPHS has also been found to negatively correlate with help seeking stigma $(\mathrm{r}=-.40),[18,19]$.

The overall score represented how positive an individual's attitude toward seeking professional psychological help is. A total of 11 items were positively stated while 18 items are negatively stated. Negative items were reverse scored. Scores ranged from 29-116 and a high score indicates a positive attitude towards professional psychological help seeking.

\subsection{Study Design and Sampling}

This is part of a larger longitudinal quasi-experimental (intervention) study, "The effects of psychoeducation on attitudes towards mental health seeking behaviour among primary school teacher trainees in Kenya".

Convenience sampling was used to sample the four colleges out of the 20 public teacher-training colleges as it was also learned that recruitment to colleges covered the all country on a quota system and all students were recruited for the study in the four colleges in order to increase generalizability of results.

\subsection{Study Procedure}

Four psychologists were trained as research assistants. This team assisted the researchers in explaining the purpose, importance, and rationale of the study and how to fill out the questionnaires to the participants.

Participants were asked to fill out the self-administered demographic and ATPPHS questionnaires in a single session while sited in their normal classrooms. The average number of students in a class was 42. Each set of questionnaires consisted of a consent form. Consent forms were given and explained and those who consented went on to fill the questionnaire and placing them in a sealed box placed in the front of the classroom. Those who did not consent folded the questionnaires and placed them inside the sealed box too.

\subsection{Ethical Considerations}

The Kenyatta National Hospital and the University of
Nairobi Ethics Committee (KNH/UON-EC) protocol which sets forth research ethics concerning individuals personal data was strictly adhered to, to ensure ethical considerations and confidentiality. The researchers also got authority from the Ministry of Education, (Research Department) who also informed the District Commissioners and District Education Officers of the respective Districts of the study.

The participants were explained the purpose of the study and an informed written consent was obtained before participants went on to fill the questionnaires. The participants were assured of their confidentiality and were informed that (1) participation was voluntary and they could withdraw from the research anytime if they wanted to with no penalties, (2) no names were to be used to identify them although admission numbers were used, but later coded before data were entered into the computer, (3) results would be reported in terms of groups but not as individuals.

The participants were also informed that there would be no physically intrusive procedures although some of the questions could emotionally be painful. Those who may realize discomfort during or after answering the questionnaires could see the Guidance and Counseling Department at the College or any member of the research team of psychologists (assisting in data collection) or contact the researcher or the supervisors for the research and contacts were provided.

\subsection{Data Management and Analysis}

Collected data was coded before entering into the computer. All statistical data entry and statistical analysis was done using SPSS Version 19.0. Continuous data was described with means and standard deviations while categorical data was presented as frequencies and percentages. Cross-group comparisons of ATTPHS scores were conducted using one-way analysis of variance (ANOVA) and the student t-test. These results are presented in tables.

\section{Results}

\subsection{Participants Characteristics}

The sample consisted of 2777 teacher trainees, with 1466 $(52.8 \%)$ being female, $605(21.8 \%)$ were 20 years of age and under, $1664(59.9 \%)$ were between 21 and 25 years of age, and $508(18.3 \%)$ were over 25 years of age. $1274(45.9 \%)$ were first years, $597(21.5 \%)$ were married, 2 (0.1\%) were widowed, $21(0.8 \%)$ were divorced or separated and 2157 $(77.7 \%)$ were not married. Those who were Christians were $2665(96.0 \%)$, while those who were Muslims were 82 $(3.0 \%)$ and others were $29(1.0 \%)$. Those who had taught before coming to college were 1171 (42.2\%).

\subsection{Level of Summative Scores on Attitudes towards Professional Psychological Help Seeking Based on the Participants}

$22.51 \%, 77.49 \%$ and $0 \%$ were found on negative, moderate/neutral and positive summative scores on Attitudes towards Professional Psychological help seeking among 
these participants as indicated on diagram 1 below.

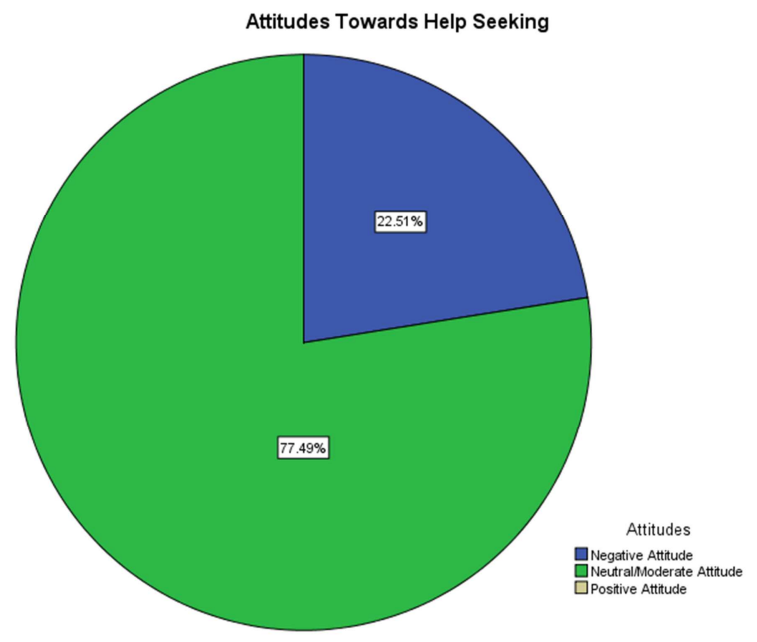

Figure 1. Summative Scores on Attitudes Towards Professional Psychological Help Seeking.

\subsection{Levels of Attitudes Towards Professional Psychological Help Seeking Summative Score Based on Demographic Characteristics of the Participants}

Based on the demographic characteristics of this population, significant variation $(\mathrm{p}=.000)$ was indicated in year of study, gender, marital status, and whether they ever taught before coming to college. The second years and female participants held more favourable attitudes towards professional psychological help seeking compared to the first years and male participants respectively. In addition significant variation indicated by marital status and whether ever taught before coming to college was because the separated, widowed and divorced and those who taught before coming to college held more favourable attitudes towards professional psychological help seeking compared to the married and those who had not taught before coming to college respectively, as indicated in Table 1 below.

Table 1. Presents the mean summative scores of the ATTPPHS Scale based on Demographic Characteristics.

\begin{tabular}{|c|c|c|c|c|c|c|}
\hline \multicolumn{2}{|c|}{ Demographic Characteristics } & \multicolumn{3}{|c|}{ ATPPHS Scale Statistic Scores } & \multicolumn{2}{|l|}{ Tests } \\
\hline Factor & Category & $\mathbf{n}$ & mean & SD & $\mathbf{F}$ & $\mathbf{S}$ \\
\hline \multirow{2}{*}{ Year of Study } & First year & 1281 & 60.128 & 5.795 & \multirow{2}{*}{345.125} & \multirow{2}{*}{$.000^{* *}$} \\
\hline & Second Year & 1496 & 64.382 & 6.205 & & \\
\hline \multirow{3}{*}{ Age Group in years } & $20 \&$ Below & 609 & 61.854 & 6.002 & \multirow{3}{*}{4.315} & \multirow{3}{*}{0.130} \\
\hline & $21-25$ & 1658 & 62.698 & 6.518 & & \\
\hline & Over 25 & 510 & 62.19 & 6.304 & & \\
\hline \multirow{2}{*}{ Gender } & Male & 1466 & 65.093 & 6.219 & \multirow{2}{*}{679.027} & \multirow{2}{*}{$.000 * *$} \\
\hline & Female & 1311 & 59.43 & 5.097 & & \\
\hline \multirow{3}{*}{ Religion } & Christian & 2665 & 62.438 & 6.37 & \multirow{3}{*}{0.407} & \multirow{3}{*}{0.666} \\
\hline & Muslim & 82 & 61.793 & 6.635 & & \\
\hline & Others & 29 & 62.448 & 6.522 & & \\
\hline \multirow{3}{*}{ Marital Status } & Married & 597 & 63.395 & 6.779 & \multirow{3}{*}{8.385} & \multirow{3}{*}{$.000 * *$} \\
\hline & Not Married & 2158 & 62.141 & 6.223 & & \\
\hline & Others & 22 & 66.7 & 6.783 & & \\
\hline \multirow{2}{*}{ Taught before } & yes & 1173 & 63.844 & 7.012 & \multirow{2}{*}{105.139} & \multirow{2}{*}{$.000 * *$} \\
\hline & no & 1604 & 61.378 & 5.648 & & \\
\hline \multirow{2}{*}{ Grew up } & Village & 2374 & 62.319 & 6.399 & \multirow{2}{*}{4.046} & \multirow{2}{*}{0.440} \\
\hline & Town & 403 & 63.0 .10 & 6.223 & & \\
\hline
\end{tabular}

\subsection{Levels of Attitudes Towards Professional Psychological Help Seeking Based on ATPPHS Factors}

Based on ATPPHS four factors, the following were indicated per factor:

Factor 1: Tolerance of the Stigma Associated with Psychiatric Help; significant variation was found in year of study $(\mathrm{p}=0.000)$, gender $(\mathrm{p}=0.000)$, and whether ever taught before coming to college, $(\mathrm{p}=0.004)$, table 2 below.

Factor 2: Recognition of Personal Need for Professional Help; significant variation was indicated in year of study
( $p=0.000)$, gender $(p=0.000)$, Marital Status $(0.003)$ and whether ever taught before coming to college $(p=0.000)$, table 2 below.

Factor 3: Interpersonal Openness regarding ones Problems: significant variation was found in year of study $(p=0.000)$, gender $(p=0.000)$ and whether ever taught before coming to college, $(\mathrm{p}=0.000)$, table 2 below.

Factor 4: Confidence in the Mental Health profession significant variation was found in year of study $(\mathrm{p}=0.000)$, gender $(\mathrm{p}=0.000)$, marital status $(\mathrm{p}=0.000)$, and whether ever taught before coming to college, $(p=0.000)$, table 2 below. 
Table 2. Presents ATPPHS Factors Mean Score based on Demographic Characteristics.

\begin{tabular}{|c|c|c|c|c|c|c|c|c|c|}
\hline \multirow{3}{*}{$\begin{array}{l}\text { Demographic } \\
\text { Characteristics }\end{array}$} & & \multicolumn{8}{|c|}{ Mean summative scores of ATPPHS Factors at Baseline based on Demographics } \\
\hline & & \multicolumn{2}{|c|}{$\begin{array}{l}\text { Tolerance of the Stigma } \\
\text { Associated with } \\
\text { Psychiatric Help }\end{array}$} & \multicolumn{2}{|c|}{$\begin{array}{l}\text { Recognition of } \\
\text { Personal Need for } \\
\text { Professional Help }\end{array}$} & \multicolumn{2}{|c|}{$\begin{array}{l}\text { Interpersonal } \\
\text { openness regarding } \\
\text { ones problems }\end{array}$} & \multicolumn{2}{|c|}{$\begin{array}{l}\text { Confidence in the } \\
\text { Mental Health } \\
\text { profession }\end{array}$} \\
\hline & & Mean & SD & Mean & SD & Mean & SD & Mean & SD \\
\hline \multirow{3}{*}{ Year of Study: } & 1st Year & 35.25 & 1.90 & 16.59 & 2.81 & 14.41 & 2.58 & 16.73 & 2.83 \\
\hline & 2nd Year & 35.89 & 1.90 & 17.79 & 2.78 & 15.52 & 2.58 & 17.76 & 2.74 \\
\hline & & \multicolumn{2}{|c|}{$\mathrm{T}=-8.839, \mathrm{p}=0.000$} & \multicolumn{2}{|c|}{$\mathrm{T}=11.277, \mathrm{p}=.000$} & \multicolumn{2}{|c|}{$\mathrm{T}=11.353 \mathrm{p}=0.000$} & \multicolumn{2}{|c|}{$\mathrm{T}=9.702 \mathrm{p}=0.000$} \\
\hline \multirow{4}{*}{ Age groups in years } & 20 below & 35.60 & 1.99 & 17.09 & 2.88 & 14.76 & 2.41 & 17.12 & 2.79 \\
\hline & $21-25$ & 35.61 & 1.91 & 17.34 & 2.91 & 15.09 & 2.72 & 17.36 & 2.85 \\
\hline & Over 25 & 35.52 & 1.89 & 17.06 & 2.65 & 15.04 & 2.64 & 17.23 & 2.81 \\
\hline & & \multicolumn{2}{|c|}{$\mathrm{F}=.460 \mathrm{p}=.632$} & \multicolumn{2}{|c|}{$\mathrm{F}=2.776 \mathrm{p}=.062$} & \multicolumn{2}{|c|}{$\mathrm{F}=3.364 \mathrm{p}=.035$} & \multicolumn{2}{|c|}{$\mathrm{F}=1.764 \mathrm{p}=.172$} \\
\hline \multirow{3}{*}{ Gender } & Female & 36.00 & 1.92 & 17.95 & 2.87 & 15.61 & 2.66 & 18.06 & 2.78 \\
\hline & Male & 35.13 & 1.81 & 16.43 & 2.63 & 14.33 & 2.44 & 16.42 & 2.62 \\
\hline & & \multicolumn{2}{|c|}{$\mathrm{T}=12.28 \mathrm{p}=.000$} & \multicolumn{2}{|c|}{$\mathrm{T}=14.51 \mathrm{P}=.000$} & \multicolumn{2}{|c|}{$\mathrm{T}=13.24 \mathrm{p}=.000$} & \multicolumn{2}{|c|}{$\mathrm{T}=15.974 \mathrm{p}=.000$} \\
\hline \multirow{5}{*}{ Marital Status } & Married & 35.63 & 1.97 & 17.49 & 2.81 & 15.16 & 2.84 & 17.61 & 2.79 \\
\hline & Widowed & 36.50 & .71 & 14.50 & 2.12 & 14.50 & 2.12 & 16.50 & 2.12 \\
\hline & Divorced/separated & 36.15 & 1.57 & 18.70 & 2.60 & 15.05 & 2.96 & 19.30 & 3.92 \\
\hline & Not Married & 35.58 & 1.91 & 17.15 & 2.87 & 14.96 & 2.58 & 17.18 & 2.82 \\
\hline & & \multicolumn{2}{|c|}{$\mathrm{F}=.830 \mathrm{p}=.477$} & \multicolumn{2}{|c|}{$\mathrm{F}=4.649 \mathrm{p}=.003$} & \multicolumn{2}{|c|}{$\mathrm{F}=.860 \mathrm{p}=.461$} & \multicolumn{2}{|c|}{$\mathrm{F}=7.267 \mathrm{p}=.000$} \\
\hline \multirow{4}{*}{$\begin{array}{l}\text { Have you ever } \\
\text { taught before }\end{array}$} & Yes & 35.72 & 2.01 & 17.67 & 2.95 & 15.38 & 2.81 & 17.66 & 3.01 \\
\hline & No & 35.50 & 1.85 & 16.91 & 2.74 & 14.73 & 2.47 & 17.01 & 2.65 \\
\hline & & \multicolumn{2}{|c|}{$\mathrm{T}=2.913 \mathrm{p}=.004$} & \multicolumn{2}{|c|}{$\mathrm{T}=7.023 \mathrm{p}=.000$} & \multicolumn{2}{|c|}{$\mathrm{T}=6.447 \mathrm{p}=.000$} & $\mathrm{~T}=6.05$ & \\
\hline & Christian & 35.58 & 1.91 & 17.24 & 2.86 & 15.03 & 2.65 & 17.29 & 2.83 \\
\hline Dal:a & Muslim & 35.56 & 2.23 & 16.96 & 2.78 & 14.59 & 2.22 & 17.27 & 2.59 \\
\hline Religion & Other & 36.69 & 2.02 & 17.34 & 2.87 & 14.24 & 2.69 & 17.24 & 3.04 \\
\hline & & $\mathrm{F}=4.79$ & & $\mathrm{~F}=.391$ & & $\mathrm{~F}=2.34$ & $=0.096$ & $\mathrm{~F}=.005$ & \\
\hline & Village & 17.20 & 2.84 & 35.57 & 1.92 & 14.99 & 2.65 & 17.25 & 2.82 \\
\hline I grew up in & Town & 17.39 & 2.96 & 35.67 & 1.92 & 15.13 & 2.54 & 17.46 & 2.81 \\
\hline & & $\mathrm{F}=.852$ & & $\mathrm{~T}=-1.2$ & $=0.217$ & $\mathrm{~T}=.99$ & 0.322 & $\mathrm{~F}=-1.37$ & 0.169 \\
\hline
\end{tabular}

\section{Discussion}

There was a high return rate of $94.94 \%$ in this study. This is in line with other studies in Kenya, which registered a $100 \%$ return rate. $[21,22]$. This study population can be considered to be representative of the public TTCs in Kenya because the trainees were selected and distributed during posting at National level using a quota system which considered all regions in the country.

\subsection{Levels of Attitudes Towards Professional Psychological Help Seeking Based on Summative Scores}

Although it was assumed that most college students may have knowledge on seeking professional psychological help during secondary school education in Kenya, the overall summative mean score for ATPPHS among this population was neutral (moderate) and negative at $77.49 \%$ and 22.51 respectively; however this was consistent with other findings among college students, $[12,14,17]$. Significant variations were found in gender, year of study, marital status, and whether ever taught before coming to college between both groups.

Significant variation indicated in gender, is in line with other studies among teachers in Singapore [22] and Nigeria, [23] and college students globally, [24, 25, 26], and in Kenya [27]. Possible explanations include (1) that women have the ability to possess more open attitudes to emotions, [28]; (2) that women are known to hold higher distress and likely to face more stressful situations than the male; therefore likely to seek help due to their openness to share emotions [29]; (3) may be the fact that an admission of need for help does not contradict traditionally held stereotyped perceptions of gender appropriate behaviour for women, [29] and (4) that women traditionally have a greater comfort sharing emotional concerns and have a stronger inclination to engage in interactions that involve personal sharing compared to men. Subich 1983 as quoted by Fernandez, [30] further explains; however that men have a traditional gender role of strength, inner resolve and fewer displays of emotions, characteristics that are not consistent with typical counseling behaviours.

Second years had more favaourable attitudes towards professional psychological help. This is in line with a recent Kenyan study, [27]; which indicated that the higher the level of experience in teaching one has, the more favourable attitudes towards help seeking they are likely to hold,. Similarly other literature in Nigeria indicated that those who were in higher year of study had more favourable attitudes towards mental illness, [8].

Those who reported to be widowed, separated and divorced indicated more favorable attitudes towards professional psychological help seeking compared to those who reported to be married or unmarried. Almost no data globally was found to compare this finding; however AlKrenawi, [31] has supported this in a college student's study. He suggested that being married might mean being older and 
the fact that marriage in itself may change attitudes due to other aspects of the institution of marriage, which include extra responsibilities.

Those who taught before coming to college indicated a higher mean score. This finding has been supported in literature among undergraduate students; where the first and second years had unfavourable attitudes compared to those in the third and fourth year of study, [12]. Similarly Nyutu \& Bertel [27] reported that with more teaching experience, the more favourable the attitudes towards help seeking among teachers become. This finding is encouraging because it means that although this study population was more inclined to negative attitudes; training and teaching experience acquired later improves the teacher attitude towards professional help seeking favourably to some extent.

\subsection{Association Between Demographic Characteristics and ATPPHS Factors}

Further analysis to compare demographic characteristics and the ATPPHS Scale based on the four factors was conducted in order to determine those demographic characteristics which contributed to the levels of attitudes towards help seeking in ATPPHS factors, Table 2.

In Factor I: Tolerance with Stigma associated with Psychological Help significant variation was indicated in year of study, gender, and whether they ever taught before. The participants who were in the second year of study portrayed more favourable attitudes in tolerance of stigma related to psychological help. This finding has been attributed to the TTCS curriculum, which may have made these students to tolerate stigma. The female students reported higher tolerance towards stigma in seeking psychological help for mental illness. This finding is in line with other findings, [32]. Women have been found to be more comfortable in sharing emotional experiences and reduced stigmatization, [33]. Those who reported to have taught before coming to college indicated a higher tolerance with stigma in seeking psychological help. This finding has been attributed to experience in teaching, as explained above.

In Factor II: Recognition of Personal Need for Professional Help significant variation was indicated in year of study, gender, marital status, and whether taught before coming, similarly there was also a slight significance in religion. The second years reported a higher need for professional psychological help seeking for mental health related issues. This is in line with other studies among college students and teachers generally, [22, 23]. The female trainees had more favourable recognition need for professional help; this is consistent with other findings, among Emirati College Students, [21]. The widowed, separated and divorced indicated more favourable attitudes towards help seeking, this has been attributed to counseling which they may have gone through in the marital circumstances they may have gone through, hence recognition for need for help. Those who reported to have taught before coming to college indicated a higher recognition need for help. This has been attributed to experience in teaching where they may during teaching be exposed to need for seeking help for students from more experienced teachers [27]. A slight significance indicated in religion, where those who reported to be Muslims held less favourable recognition for need for counseling; consistent with Al-Damaki, [32] who reported that generally the Muslim communities do not see a need for help seeking, from outside the family or from a stranger.

In Factor II1: Interpersonal Openness, significant variation was indicated in year of study, age group, gender and whether taught before coming to college. Participants who were in the second year of study reported higher interpersonal openness in attitudes to seeking professional help. Female students reported more favourable interpersonal openness to seeking psychological help. This finding is consistent with other earlier findings among college students and the general population, $[17,28]$. Those who reported to have ever taught before coming to college reported more favourable openness to seeking help. As already discussed above, this has been attributed to the teaching experience, [27] among teachers in Kenya.

In Factor IV, Confidence in the Counselor, significant variation was shown in the year of study, gender, marital status, and whether they ever taught before coming to college. Those in the second year of study reported higher confidence in the counselor. This has been attributed to the TTC's curriculum which may have exposed these trainees in usefulness of counseling; therefore leading to higher confidence in the counselor. Female trainees reported higher confidence in the counselor in seeking help for a mental illness. This is consistent with other findings, [32, 34]. McCathy [29] has attributed this to the fact that females are known to face more distress and stressful situations compared to the male. Those who had taught before coming to college reported higher level in confidence in the counselor. This may be attributed to teaching experience, [27].

\section{Conclusion}

We conclude that attitudes towards professional psychological help seeking for a mental illness among young adults and college students are moderate (neutral) but more towards unfavourable (negative). Therefore we are suggesting that in order to improve these attitudes, an intervention for example psychoeducation should be given to young adults at college on mental illness and counseling expectations for a mental illness, in order to positively improve attitudes towards help seeking. Above all, adding this to the college curriculum could improve in a continuous psychoeducation on mental health and illness and expectations about counseling for a mental illness. Furthermore, there is need for further research in such an intervention in the future to verify its efficacy.

\section{Acknowledgment}

We would like to acknowledge the African Mental Health 
Foundation (AMHF) and Bibwob Malel Psychological Consultants Ltd., (MICAP), for the generous contribution they gave in terms of accessing the Internet and the journals used in this document. This research was not funded.

\section{References}

[1] World Health Organization (2004). A report on the WHO, Department of Mental Health and Substance Abuse in Collaboration with the prevention Research Centre of the Universities of Nijmegen and Maastricht, WHO HQ, Geneva

[2] Rickwood D. J., Deane F. P. and Wilson C. J. When and how do young people seek professional help for mental health problems? Med J Aust 2007; 187(7): 35.

[3] WHO Fact Sheet (218), 2001. The "undefined and Hidden Burden of Mental Health Problems. WHO HQ, Geneva, Switzerland.

[4] Ostun, T. B. The Global Burden of Mental Disorders. American Journal of Public Health, 1999; 89(9):1315-1318.

[5] Jang, Y., Kim, G., Hansen, L., \& Chiriboga, D. A. (2007). Attitudes of older Korean Americans toward mental health services. Journal of the American Geriatrics Society, 55(4), 616-620.

[6] Al-Kabbaa A. F., Al-Jehani M. \& Salih M. Prevalence of minor Psychiatric Morbidity among female teachers in girls secondary schools in Tabuk City, Saudi Arabia. Journal of Family and Community Medicine 2003, 10(2): 31-36.

[7] Nyavanga E. J., Ndetei D. M., Mathai M., \& Kuria M. W. Psychiatric Morbidity among Public Primary School Teachers at Mogotio Division, in Koibatek District. University of Nairobi, Faculty of Health Sciences, School of Medicine. Department of Psychiatry, 2009.

[8] Ani C. Kinanee J. and Ola B. Psychological Distress among Trainee Teachers in Nigeria: association with religious practice. European Journal of Educational Studies 2011; 3(1): 163-169.

[9] Moreno-Abril O., Luana-del-Castillo, J. D., Fernandez-Molina C., Jurado D., Gurpegui M. Laardelli-Claret P., and GalvezVargas R. Factors associated with psychiatric morbidity in Spanish Schoolteachers. Occupational Medicine, 2007; 57: 194-202.

[10] WHO Fact Sheet (218), 2001. The "undefined and Hidden Burden of Mental Health Problems. WHO HQ, Geneva, Switzerland.

[11] World Health Organization (2007). Promoting Mental Health: Concepts, Emerging evidence, Practice: A report of the World Health Organization, Department of Mental Health and Substance Abuse in collaboration with the Victorian Health Promotion Foundation and the University of Melbourne. World Health Organization. Geneva.

[12] Zawawi J. M. A. Psychological Help Seeking Attitudes and Personality factors among Jordanian College Students. European Journal of Social Sciences 2011; 25(4): 606-629.

[13] Chen R. and Mak W. Seeking Professional Help: Etiology and beliefs about mental illness across cultures. Journal of Counseling Psychology 2008; 55: 442-450.
[14] Eisenberg, D., Downs, M. F., Golberstein, E., \& Zivin, K. (2009). Stigma and help seeking for mental health among college students. Medical Care Research and Review, 66(5), $522-541$.

[15] Jorm A. F. Mental Health Literacy: Public Knowledge and beliefs about Mental Disorders. British Journal of Psychiatry 2000; 177: 396-401.

[16] Gulliver A, Griffiths KM, Christensen H. Perceived barriers and facilitators to mental health help-seeking in young people: a systematic review. BMC Psychiatry 2010; 10:113

[17] Suradi Salim. Psychological Help seeking attitudes among Malaysian College and University Students. Prescodia Social and Behavioural Sciences, 2010; 5: 426-430.

[18] Fischer E. H. and Turner, J. 1. Orientations to seeking professional help: Development and research utility of an attitude scale. Journal of Consulting and Clinical Psychology, 1970; 35, 79-90.

[19] Nam S. K., Chu H., Lee M. Lee J., Kim N. and Lee S. A metaanalysis of gender differences in attitudes toward seeking professional psychological help. Journal of American College Health 2010; 59(2): 110-116.

[20] Ndetei D. M., Khasakhala L., Nyabola L. Ongecha F. Seedat S. Mutiso V., and Odhiambo G. Prevalence of anxiety and depression symptoms and syndromes in Kenyan Child and Adolescent. Journal of Child and Adolescent Mental Health 2008; 20(1): 33-51.

[21] Ndetei, D. M. Khasakhala L., Nyabola L., Ongecha F and Kokonya, D. A. Psychosocial and health aspects of drug use by students in public Secondary Schools in Nairobi, Kenya. Substance Abuse 2009; 30: 61-68.

[22] Yeap R. and Low W. Y. Mental Health Knowledge, Attitudes and Help Seeking Tendencies: A Malaysian Context. Singapore Medical Journal 2009; 50(12): 1169-1176

[23] Aghukwa N. C. Secondary School Teachers Attitude to Mental Illness in Ogun State, Nigeria. African Journal of Psychiatry 2009; 1: 59-63.

[24] Hsiaowen Chang. Help-Seeking for Stressful Events Among Chinese College Students in Taiwan: Roles of Gender, Prior History of Counseling, and Help-Seeking Attitudes. Journal of College Student Development 2008; 49(1): 41-51.

[25] Ang, R. P., Lim, K. M., \& Tan, A. Effects of gender and sex role orientation on help-seeking attitudes. Current Psychology: Developmental, Learning, Personality, Social 2004; 2: 203-214.

[26] Zhi-hong, H. Predictors of college students' attitudes toward seeking professional psychological help. Paper presented in proceedings (pp. 1-4) of Bioinformatics and Biomedical Engineering (ICBBE), 2010 4th International Conference (1820 June 2010), Chengdu- China

[27] Nyutu P. N. Bertel J. M. Perceptions of teacher preparation and attitudes regarding students' mental health in Kenya. Advances in school Mental Health Promotion 2012; 5(1): 63-74.

[28] Tomaras V. D., Ginieri-Cpccossis M., Vassiliadou M., Malliori M., Ferintinos S., Soldatos C. R. and Tylee A. Education in mental health promotion and its impact on the participants' attitudes and perceived mental health. Annals of General Psychiatry 2011; 10:33. 
[29] McCathy C., Mejia O. 1., Liu H. I. and Duncan A. C. Cognitive appraisal theory: a psycho-educational model for connecting thoughts and feelings in multicultural group work. Paper presented at the Annual Convention of American Psychological Association 2010, San Francisco, CA.

[30] Fernandez J. I. The effects of athletic participation, expectations about counseling behaviours among community college students. Unpublished dissertation submitted in partial fulfillment of the degree of Doctor of Education, 2005; University of Central Florida, Orlando, Florida,

[31] Ak-Krenawi A., Graham J. R. Al-Bedah E. A., Kadri H. M. and Sehawail M. A. Cross-national comparison of Middle Eastern university students: Help seeking behaviours, attitudes toward helping professionals, and cultural beliefs about mental health problems. Community Mental Health Journal 2009; 45: 26-36.

[32] Al-Darmaki F. Attitudes towards seeking professional psychological help: What really counts for United Arab Emirates University Students? Social Behaviour and Personality. An International Journal 2003, 31(5): 497.

[33] Zhi-hong, H. Predictors of college students' attitudes toward seeking professional psychological help. Paper presented in proceedings (pp. 1-4) of Bioinformatics and Biomedical Engineering (ICBBE), 2010 4th International Conference (1820 June 2010), Chengdu- China.

[34] Kakhnovets, R. (2011). Relationships among personality, expectations about counseling, and help-seeking attitudes. Journal of Counseling and Development: JCD, 89(1), 11. 